\title{
Intravenous Dipyridamole Enhances the Effects of Inhaled Nitric Oxide and Prevents Rebound Pulmonary Hypertension in Piglets
}

\author{
LUC FOUBERT, DANIËL DE WOLF, KATTY MAREELS, YVES VAN BELLEGHEM, \\ KOEN REYNTJENS, ERIC MORTIER, AND GUIDO VAN NOOTEN
}

Department of Anesthesia, Division of Cardiac Anesthesia [L.F., K.M., K.R., E.M.], Department of Pediatrics, Division of Pediatric Cardiology [D.D.W.], Department of Cardiac Surgery [Y.V.B., G.V.N.], University Hospital Ghent, Gent, Belgium; Laboratory for Experimental Cardiac Surgery, University of Ghent, Gent, Belgium [L.F., D.D.W., Y.V.B., K.R., E.M., G.V.N.]

\begin{abstract}
Inhaled nitric oxide (NO) is increasingly used in the treatment of pulmonary hypertension, despite its potential toxicity and the risk of life-threatening rebound pulmonary hypertension upon its discontinuation. We investigated whether i.v. dipyridamole, a cGMP phosphodiesterase inhibitor, increased the effects of inhaled NO and prevented rebound pulmonary hypertension. In 14 anesthetized and mechanically ventilated piglets, pulmonary hypertension was induced with U-46619, a thromboxane $\mathrm{A}_{2}$ analogue. Response to NO and rebound pulmonary hypertension were evaluated without and with i.v. dipyridamole. Low-dose dipyridamole $(10 \mu \mathrm{g} / \mathrm{kg} / \mathrm{min})$ increased cardiac output and augmented the effects of inhaled NO on pulmonary vascular resistance, with marginal additive effect on mean pulmonary artery pressure. Pulmonary vascular resistance decreased from 904 to 511 (20 parts per million NO) $(p<0.0005)$ and 358 dyne $\mathrm{s} \mathrm{cm}^{-5}$ (20 parts per million $\mathrm{NO}+$ dipyridamole) $(p<0.001$ versus $\mathrm{NO}$ alone), and mean pulmonary artery pressure decreased from 29.0 to 20.5 ( $p<0.0001$ ) and $19.3 \mathrm{~mm} \mathrm{Hg}$ (NS versus NO), respectively. Mean arterial pressure decreased from 85 to $74 \mathrm{~mm} \mathrm{Hg}$ (dipyridamole + NO) $(p<0.01)$. High-dose dipyridamole $(100$ $\mu \mathrm{g} / \mathrm{kg} / \mathrm{min}$ ) with inhaled NO reduced pulmonary vascular resis-
\end{abstract}

\section{ABSTRACT}

tance to 334 dyne $\mathrm{s} \mathrm{cm}^{-5}$ but also decreased mean arterial pressure to $57 \mathrm{~mm} \mathrm{Hg}$. Eight piglets developed rebound pulmonary hypertension. Two died of acute right ventricular failure and, in five, rebound pulmonary hypertension was prevented by low-dose dipyridamole. In conclusion, low-dose i.v. dipyridamole augments the effects of inhaled NO on right ventricular afterload with moderate changes in systemic hemodynamics, and can prevent rebound pulmonary hypertension. (Pediatr Res 52: 730-736, 2002)

CO, cardiac output

\section{Abbreviations}

MAP, mean arterial pressure

MPAP, mean pulmonary artery pressure

NO, nitric oxide

$\mathrm{NO}_{2}$, nitrogen dioxide

PDE 5, phosphodiesterase type 5

PHT, pulmonary hypertension

ppm, parts per million

PVR, pulmonary vascular resistance

SVR, systemic vascular resistance
$\mathrm{NO}$ is a potent endothelium-derived relaxing factor that exerts its vasodilating action through stimulation of soluble guanylyl cyclase and subsequent increase in cGMP in the vascular smooth muscle cell (1-3), where it is rapidly hydrolyzed by cGMP-specific phosphodiesterases (PDE 5) (4, 5). Since its introduction as a selective pulmonary vasodilator, inhaled NO $(5,6)$ has been used in a variety of pathologies associated with PHT, including adult respiratory distress syndrome, persistent PHT of the newborn, and in adult and

Received June 18, 2001; accepted July 11, 2002.

Correspondence: Luc Foubert, M.D., D.Sc., Department of Anesthesia and Intensive Care, OLV Clinic Aalst, Moorselbaan 164, 9300 Aalst, Belgium; e-mail: Luc.Foubert@olvz-aalst.be

DOI: 10.1203/01.PDR.0000032067.33728.CF neonatal cardiac surgery (7-10). Despite these beneficial effects, two major problems are a cause for concern. First, the safety of long-term inhalation of NO has not been fully elucidated. The maximal exposure limit of $25 \mathrm{ppm}$ NO for $8 \mathrm{~h}$ a day, set by the Occupational Safety and Health Administration (11), may not be safe in patients with PHT who are receiving NO continuously for a prolonged period and who, additionally, are likely to have an abnormal pulmonary circulation. Second, severe rebound PHT on sudden withdrawal of inhaled NO has been described previously $(12,13)$.

Because cGMP phosphodiesterase (PDE 5) inhibitors induce pulmonary vasodilation (14-16), we investigated whether dipyridamole, a clinically available cGMP phosphodiesterase inhibitor, could enhance the effects of inhaled NO in experi- 
mentally induced PHT in piglets. This could result in lower concentrations of inhaled NO to be effective and may consequently reduce potential toxicity associated with NO inhalation. We also hypothesized that increased plasma cGMP levels, expected as a result of dipyridamole infusion, could prevent rebound PHT on withdrawal of inhaled NO.

\section{METHODS}

The experiments were performed in accordance with institutional guidelines for animal research.

\section{Animal Selection and Surgical Procedures}

Fourteen healthy piglets (age 5-6 wk; weight $10-12.5 \mathrm{~kg}$ ) were studied under general anesthesia. None of the piglets had any sign of pulmonary or other infection.

Thirty minutes before induction of anesthesia, the piglets were premedicated with azaperone $(8 \mathrm{mg} / \mathrm{kg}$ intramuscularly). General anesthesia was induced with i.v. sodium thiopental (10 $\mathrm{mg} / \mathrm{kg})$ and pancuronium $(0.15 \mathrm{mg} / \mathrm{kg})$ injected in an ear vein. The animals were intubated and mechanically ventilated (fraction of inspired oxygen 0.40 and arterial $\mathrm{PCO}_{2} 5.3-6 \mathrm{kPa}$ ). Anesthesia was maintained with propofol $(160-200 \mu \mathrm{g} / \mathrm{kg} /$ $\mathrm{min})$, sufentanil $(0.03 \mu \mathrm{g} / \mathrm{kg} / \mathrm{min})$, and pancuronium (7 $\mu \mathrm{g} / \mathrm{kg} / \mathrm{min}$ ).

After surgical incision, a 20-gauge catheter (Vygon, Ecouen, France) was introduced into the right carotid artery and positioned in the aorta for blood pressure monitoring and sampling of cGMP and arterial blood gases (288 Blood Gas System, Chiron, Emeryville, CA, U.S.A.). Pulmonary artery pressures and $\mathrm{CO}$ were measured with a $5 \mathrm{~F}$ thermodilution catheter (Baxter Healthcare, Deerfield, IL, U.S.A.) introduced via the right external jugular vein. The left external jugular vein was cannulated with a 5F three-lumen catheter (William Cook Europe ApS, Bjaeverskov, Denmark) for measurement of central venous pressure and administration of dipyridamole and i.v. fluids. U-46619 was administered via a 20-gauge catheter (Vygon) positioned in a femoral vein. ECG and invasive blood pressures were monitored with an HP 78304 A monitor (Hewlett Packard, Palo Alto, CA, U.S.A.). The animals were positioned on a heated water pad to maintain rectal temperature between 38.5 and $39.5^{\circ} \mathrm{C}$.

\section{Delivery of Inhaled NO}

Medical-grade NO from a $1000 \mathrm{ppm}$ NO cylinder (BOC, Guildford, Surrey, U.K.) was delivered before the ventilator via a nitrogen rotameter to obtain inspiratory concentrations of $2.5,5,10$, and $20 \mathrm{ppm}$. Inhaled $\mathrm{NO}$ and $\mathrm{NO}_{2}$ concentrations were continuously monitored with a fast response chemiluminescence analyzer (NOX 4000, Seres, Aix-en-Provence, France) at the level of the endotracheal tube.

\section{Drug Preparation}

A stock solution of U-46619 $(10 \mathrm{mg} / \mathrm{mL}$, Pharmacia, Peapack, NJ, U.S.A.) was stored at $-20^{\circ} \mathrm{C}$. Immediately before the experiments, $0.5 \mathrm{mg}$ of U-46619 was dissolved in $50 \mathrm{~mL}$ of Ringer lactate. Dipyridamole $(10 \mathrm{mg} / 2 \mathrm{~mL}$, Boehringer In- gelheim, Ingelheim, Germany) was diluted in $0.9 \%$ saline to a final concentration of $0.25 \mathrm{mg} / \mathrm{mL}$ (part A) and $1 \mathrm{mg} / \mathrm{mL}$ (part B) in the second protocol.

\section{Measurement of Plasma cGMP}

Plasma cGMP concentrations were determined in eight piglets using ${ }^{125}$ I RIA (Immunotech, Biocode, Liege, Belgium). For each cGMP measurement, $1 \mathrm{~mL}$ of blood was sampled from the arterial line and cooled in ice. Within $5 \mathrm{~min}$, the samples were centrifuged during $10 \mathrm{~min}$ in a cooled $\left(4^{\circ} \mathrm{C}\right)$ centrifuge (Hettich Universal 16 R, Hettich-Zentrifugen, Tuttlingen, Germany) at $2500 \times g$. Plasma was separated and stored at $-20^{\circ} \mathrm{C}$ until the assay was performed. Plasma cGMP concentrations were measured using competitive binding of sample and known amounts of ${ }^{125}$ I-labeled cGMP for a specific antibody. All samples were determined in duplicate and intraand interassay quality were controlled by measuring a known amount of cGMP. Plasma cGMP concentrations are expressed as picomoles per milliliter plasma.

\section{Experimental Protocol 1: Response to Inhaled NO}

After 20 min of stable baseline conditions, an infusion of a potent pulmonary vasoconstrictor U-46619, a stable endoperoxide analogue of thromboxane $\mathrm{A}_{2}$ (9,11-dideoxy- $9 \alpha, 11 \alpha$ epoxymethanoprostaglandin $\mathrm{F}_{2 \alpha}$ ) was titrated at a rate of 0.03 $0.06 \mu \mathrm{g} / \mathrm{kg} / \mathrm{min}$ to increase MPAP to $170-180 \%$ of baseline values. When MPAP was stable for $10 \mathrm{~min}$, incremental doses of inhaled $\mathrm{NO}(2.5,5,10$, and $20 \mathrm{ppm})$ were delivered over 5 min for each concentration and hemodynamic measurements were performed at each $\mathrm{NO}$ concentration. $\mathrm{CO}$ was measured as the average of two determinations after injection of $5 \mathrm{~mL}$ normal saline at room temperature. Thereafter, NO was discontinued and MPAP was recorded every minute over $10 \mathrm{~min}$ to detect rebound PHT, which was defined as an elevation of at least $20 \%$ above values obtained with U-46619. After this 10-min period, the infusion of U-46619 was discontinued for $20 \mathrm{~min}$ to allow the right ventricle to recover from the high afterload and to prevent right ventricular dysfunction.

\section{Experimental Protocol 2: Response to Inhaled NO with Intravenous Dipyridamole}

Twenty minutes after the end of protocol 1, MPAP was increased again with U-46619, as in protocol 1.

Part $\boldsymbol{A}$. Intravenous dipyridamole was infused at $10 \mu \mathrm{g} / \mathrm{kg} /$ $\min$ in the 12 surviving piglets and continued throughout the experiment. Hemodynamic measurements were performed at 5 and $10 \mathrm{~min}$, after which protocol 1 was repeated. Again, a 10-min NO-free period was repeated to monitor rebound PHT while dipyridamole was continued.

Part B. Fifteen minutes after NO was stopped, dipyridamole was increased to $100 \mu \mathrm{g} / \mathrm{kg} / \mathrm{min}$. Again, the response to inhaled NO was repeated. In this experiment, however, dipyridamole was not continued until the end of the experiment, but stopped together with the last dose of NO (Fig. 1).

Plasma cGMP concentrations were measured in eight piglets at baseline, during infusion of U-46619, during dipyridamole 


\begin{tabular}{|c|c|c|c|c|c|}
\hline & $2.5 \mathrm{NO}-5 \mathrm{~min}$ & $5 \mathrm{NO}-5 \mathrm{~min}$ & $10 \mathrm{NO}-5 \mathrm{~min}$ & $20 \mathrm{NO}-5 \mathrm{~min}$ & stop NO - $10 \mathrm{~min}$ \\
\hline Baseline & \multicolumn{5}{|c|}{ U-46619 } \\
\hline
\end{tabular}
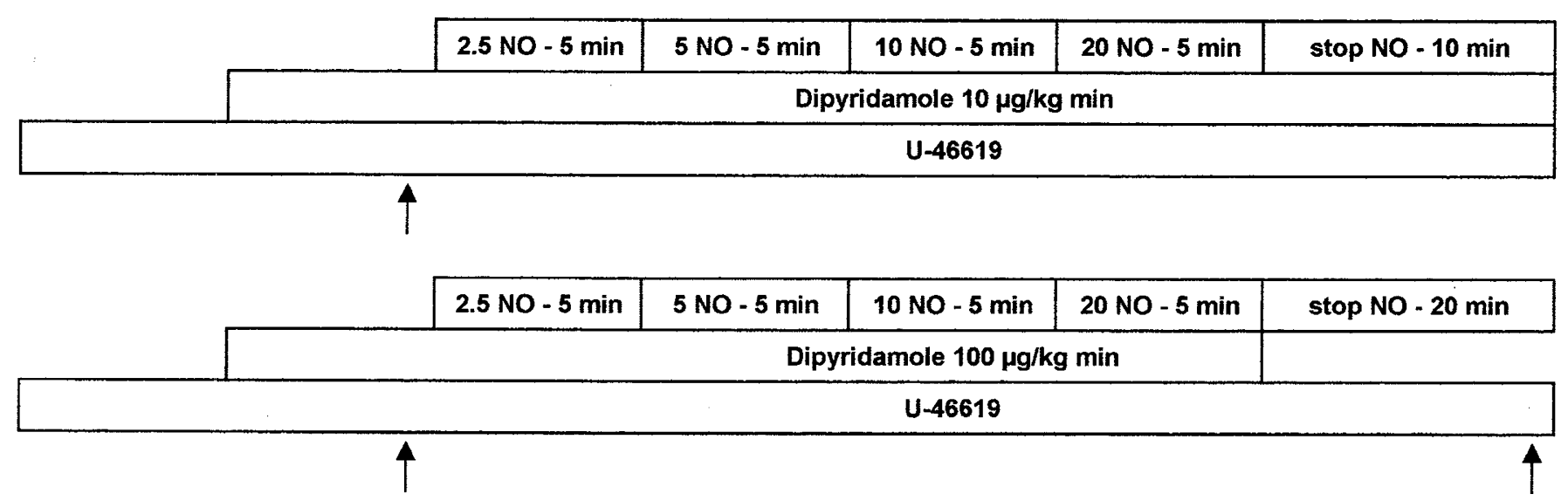

Figure 1. Schematic representation of study protocol 1, 2A, and 2B. NO in ppm. Each NO dose was administered during 5 min. Hemodynamic measurements were performed at baseline, during U-46619, and at the end of each NO dosing period. Arrows indicate time points for cGMP measurements.

infusion (10 and $100 \mu \mathrm{g} / \mathrm{kg} / \mathrm{min}$ ), and $20 \mathrm{~min}$ after the highdose dipyridamole $(100 \mu \mathrm{g} / \mathrm{kg} / \mathrm{min})$ was stopped.

\section{Statistical Analysis}

Data are presented as means \pm SD. Statistical analysis was performed with SigmaStat (SPSS Science, Chicago, IL, U.S.A) using two-way ANOVA for repeated measures for analysis within and between groups. A $p$ value $<0.05$ was considered significant.

\section{RESULTS}

Two piglets died of acute right ventricular failure resulting from extreme rebound PHT after withdrawal of inhaled NO at the end of protocol 1 , and consequently did not receive a dipyridamole infusion. Data obtained from these animals were not used for statistical analysis. All 12 surviving piglets completed the entire study protocol. All data shown comprise these 12 piglets, except when mentioned otherwise. $\mathrm{NO}_{2}$ concentrations were $<0.3 \mathrm{ppm}$ at all times, and a $5 \%$ difference between the delivered and the aimed NO concentration was considered acceptable.

\section{Protocol 1}

Infusion of U-46619 increased MPAP from $16.6 \pm 1.6$ to $29.0 \pm 2.6 \mathrm{~mm} \mathrm{Hg}(p<0.0001)$ and PVR from $353 \pm 76$ to $904 \pm 183$ dyne $\mathrm{s} \mathrm{cm}^{-5}(p<0.0001)$. MAP increased from 74 \pm 14 to $90 \pm 14 \mathrm{~mm} \mathrm{Hg}(p<0.001)$, SVR increased from $2671 \pm 772$ to $3548 \pm 779$ dyne $\mathrm{s} \mathrm{cm}^{-5}(p<0.001)$, and CO decreased from $2.1 \pm 0.2$ to $1.9 \pm 0.2 \mathrm{~L} / \mathrm{min}(\mathrm{NS})$.

Inhaled NO significantly decreased both MPAP and PVR at all concentrations (Table 1) without changes in systemic hemodynamic parameters. There were no significant changes in central venous pressure and pulmonary capillary wedge pressure $(\mathrm{PcwP})$ during the experiment. The response to inhaled
NO showed 5, 10 and $20 \mathrm{ppm}$ NO to be more effective than 2.5 ppm both for MPAP and PVR, whereas only 20 ppm was significantly different from 5 ppm (Fig. 2). Rebound PHT occurred in six of the surviving twelve piglets within $2 \mathrm{~min}$ after NO was discontinued, with a peak after $5 \mathrm{~min}$. MPAP ( $n$ =6) increased from $29.8 \pm 2.9 \mathrm{~mm} \mathrm{Hg}$ to $36.8 \pm 4.7(p<$ $0.04)$ and $41.0 \pm 4.8 \mathrm{~mm} \mathrm{Hg}(p<0.001)$ at 2 and $5 \mathrm{~min}$, respectively (Fig. 3).

\section{Protocol 2}

Part A. Restarting the infusion of U-46619 resulted in a MPAP of $29.7 \pm 2.6 \mathrm{~mm} \mathrm{Hg}$ and a PVR of $966 \pm 246$ dyne $\mathrm{s} \mathrm{cm}^{-5}$. Ten minutes of i.v. dipyridamole $(10 \mu \mathrm{g} / \mathrm{kg} / \mathrm{min})$ reduced MPAP and PVR, but also MAP and SVR with a concomitant increase in CO. Heart rate increased from $126 \pm$ 18 to $138 \pm 27$ beats/min (NS) after $10 \mathrm{~min}$ of dipyridamole infusion. Addition of inhaled NO further decreased PVR to levels below those obtained with inhaled $\mathrm{NO}$ alone (at all $\mathrm{NO}$ concentrations) without further alterations in systemic hemodynamics, except for an additional increase in CO (Table 1).

In five of the six piglets with rebound PHT in protocol 1, dipyridamole infusion completely prevented rebound PHT (Fig. 3). In one piglet, dipyridamole failed to prevent rebound PHT. In this animal, MPAP increased from 33 to $43 \mathrm{~mm} \mathrm{Hg} 6$ min after withdrawal of $\mathrm{NO}$, but decreased to $37 \mathrm{~mm} \mathrm{Hg} 10$ min after NO discontinuation.

Part B. Dipyridamole at $100 \mu \mathrm{g} / \mathrm{kg} / \mathrm{min}$ reduced both MPAP and PVR, but also induced a profound systemic vasodilation and increased CO. Furthermore, HR increased significantly from $126 \pm 18$ before the high-dose dipyridamole infusion to $149 \pm 19$ beats/min $(p<0.02)$. However, most of the HR increase occurred during the $\mathrm{NO}$ withdrawal period, irrespective of whether dipyridamole was administered or not. Filling pressures decreased slightly, but the changes were not statisti- 


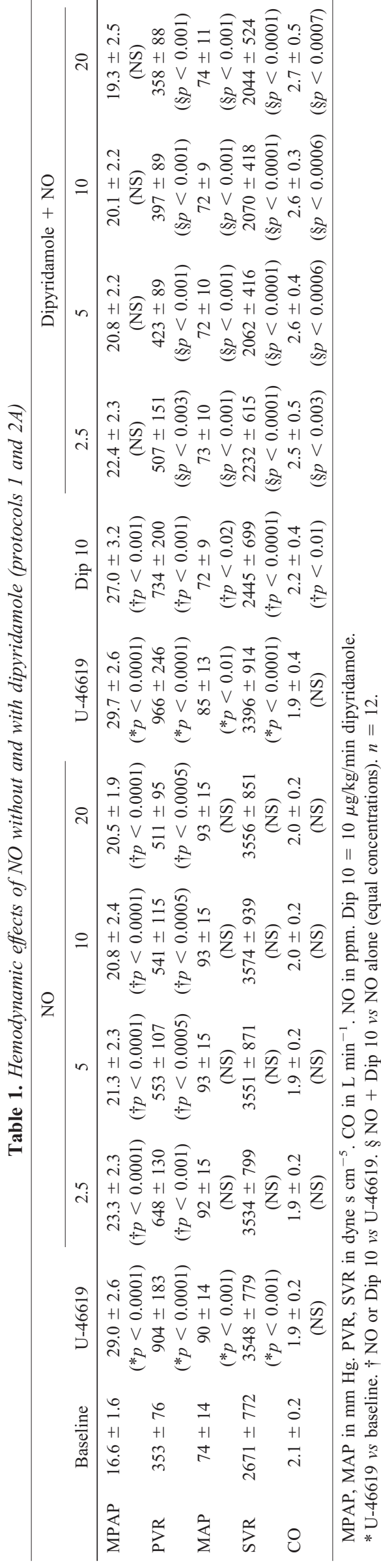

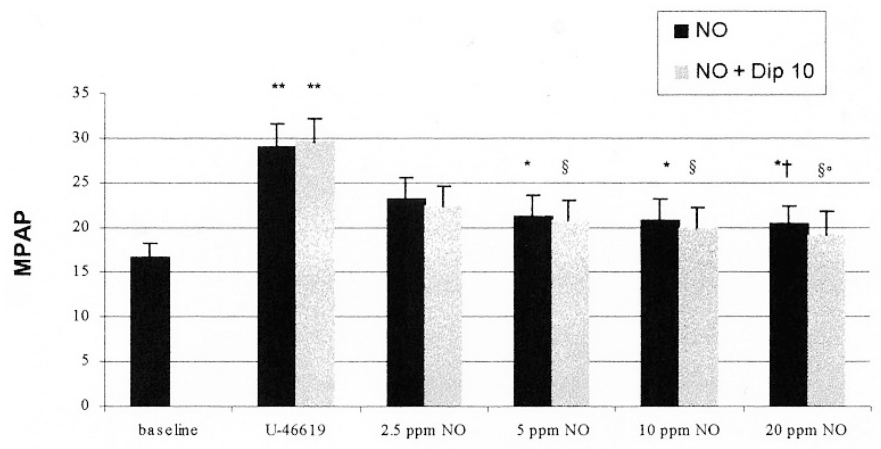

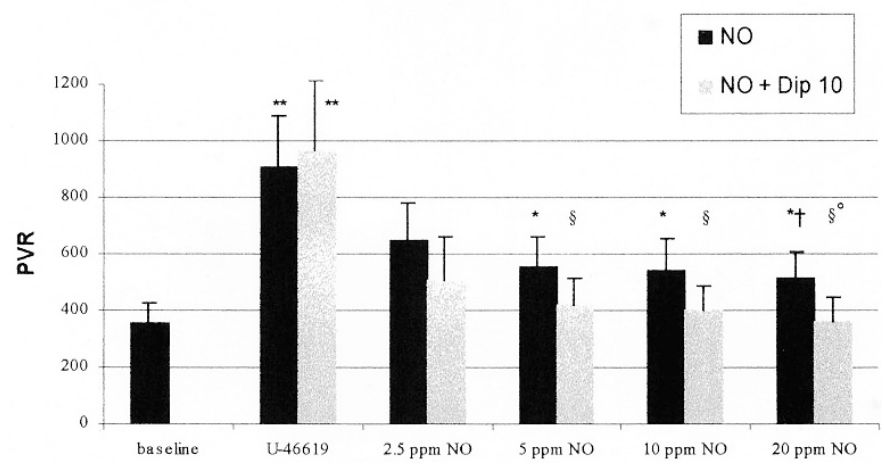

Figure 2. Response to inhaled NO (protocol 1 and 2A): effects on MPAP $(\mathrm{mm} \mathrm{Hg})$ and PVR (dyne s $\mathrm{cm}^{-5}$ ). NO in ppm. Dip 10, dipyridamole 10 $\mu \mathrm{g} / \mathrm{kg} / \mathrm{min}$. Data are mean $\pm \operatorname{SD}(n=12)$. Control: data from protocol 1. Dip: data from protocol 2a. For MPAP: ${ }^{*} p<0.001$ vs $2.5 \mathrm{NO}, \dagger p<0.01$ vs $5 \mathrm{NO}$, $\S p<0.01 v s 2.5 \mathrm{NO}+\operatorname{Dip} 10,{ }^{\circ} p<0.01$ vs $5 \mathrm{NO}+$ Dip $10,{ }^{*} p<<0.0001$ vs baseline. For PVR: $* p<0.01$ vs $2.5 \mathrm{NO}, \dagger p<0.05$ vs $5 \mathrm{NO}, \S p<0.01$ vs $2.5 \mathrm{NO}+$ Dip $10,{ }^{\circ} p<0.05$ vs $5 \mathrm{NO}+$ Dip, $* * p<0.0001$ vs baseline.

cally significant. Central venous pressure and PcwP decreased from $6.2 \pm 3.0$ to $5.6 \pm 2.4$ (NS) and from $7.2 \pm 1.8$ to $7.1 \pm$ $2.2 \mathrm{~mm} \mathrm{Hg}(\mathrm{NS})$. Inhalation of NO further reduced MPAP and PVR without major changes in systemic hemodynamics, except a further increase in $\mathrm{CO}$ (Table 2). None of the animals experienced rebound PHT, despite simultaneous cessation of i.v. dipyridamole infusion and inhalation of $\mathrm{NO}$, not even 20 min after both drugs were discontinued, suggesting prolonged protection of dipyridamole against rebound PHT. In fact, MPAP remained significantly lower versus U-46619.

Plasma cGMP concentrations $(n=8)$ increased from baseline values of $11.7 \pm 2.1$ to $15.3 \pm 3.5(p<0.006)$ and 16.5 $\pm 5.1(p<0.05) \mathrm{pmol} / \mathrm{mL}$ at 10 and $100 \mu \mathrm{g} / \mathrm{kg} / \mathrm{min}$ dipyridamole, respectively (Fig. 4). Even 20 min after dipyridamole and NO administration were stopped, these high cGMP levels were maintained at $15.6 \pm 4.9 \mathrm{pmol} / \mathrm{mL}(p<0.05)$.

\section{DISCUSSION}

NO produced by pulmonary vascular endothelial cells is an important modulator of pulmonary vascular tone $(17,18)$. Because PHT may be associated with attenuated endogenous NO production $(18,19)$ and persistent or increased cGMP phosphodiesterase activity (16), the combination of NO with a cGMP phosphodiesterase inhibitor might reduce the effective 


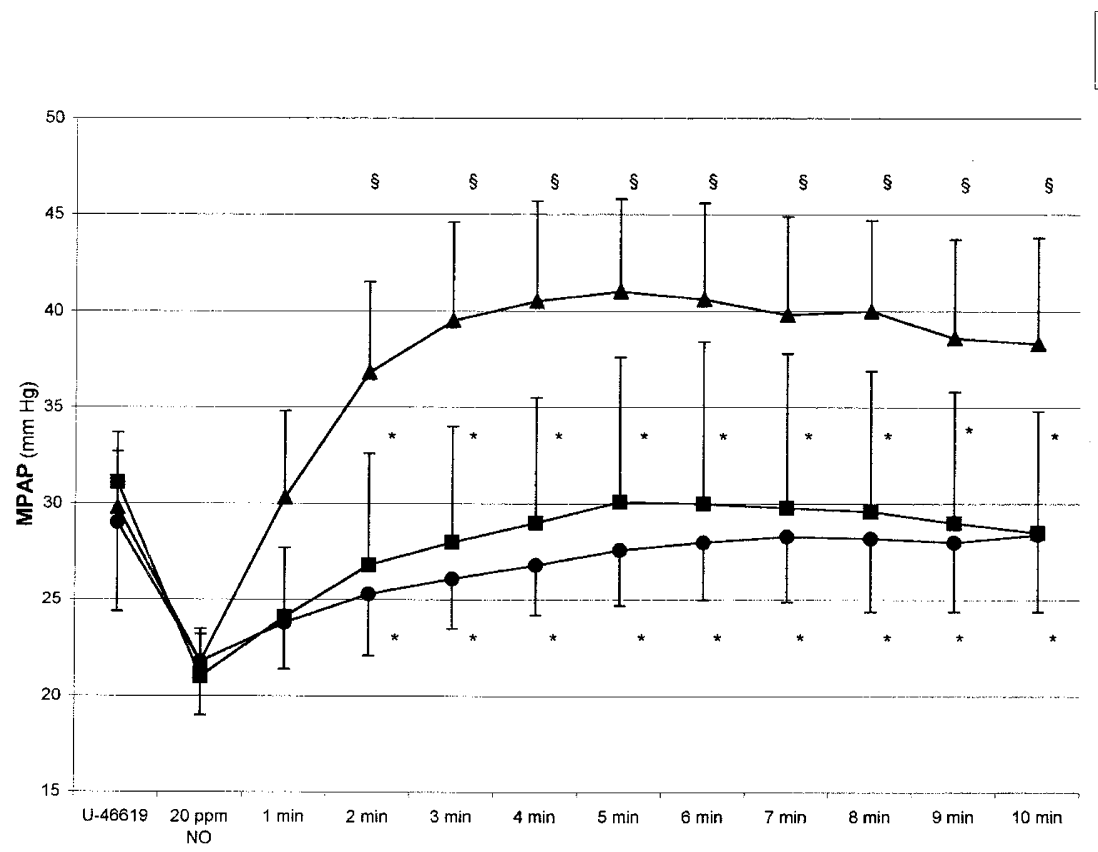

Figure 3. Rebound PHT $(n=6)$ occurred within 2 min after withdrawal of 20 ppm NO. 1-10 min = data collected every minute after NO withdrawal over 10 min. Both Dip 10 and Dip 100 prevented rebound PHT. Data are mean \pm SD. ${ }^{*} p<0.05 v s$ NO without dipyridamole, $\S p<0.05 v s$ U-46619.

Table 2. Effects of Dip 100 vs NO (protocol 2B)

\begin{tabular}{|c|c|c|c|c|c|c|c|c|}
\hline & Baseline & U-46619 & $2.5 \mathrm{NO}$ & $20 \mathrm{NO}$ & Dip 100 & $\begin{array}{c}\text { Dip } 100+2.5 \\
\mathrm{NO}\end{array}$ & $\begin{array}{c}\text { Dip } 100+20 \\
\text { NO }\end{array}$ & Stop Dip 100 \\
\hline MPAP & $16.6 \pm 1.6$ & $\begin{array}{c}29.7 \pm 2.6 \\
\left({ }^{*} p<0.0001\right)\end{array}$ & $\begin{array}{c}23.3 \pm 2.3 \\
(\dagger p<0.0001)\end{array}$ & $\begin{array}{c}20.5 \pm 1.9 \\
(\dagger p<0.0001)\end{array}$ & $\begin{array}{c}23.5 \pm 2.3 \\
(\dagger p<0.0001)\end{array}$ & $\begin{array}{c}21.1 \pm 2.5 \\
(\mathrm{NS})\end{array}$ & $\begin{array}{c}19.9 \pm 2.8 \\
\text { (NS) }\end{array}$ & $\begin{array}{c}28.5 \pm 4.1 \\
(\dagger p<0.01)\end{array}$ \\
\hline MAP & $74 \pm 14$ & $\begin{array}{c}85 \pm 13 \\
\left({ }^{*} p<0.01\right)\end{array}$ & $\begin{array}{c}92 \pm 15 \\
(\mathrm{NS})\end{array}$ & $\begin{array}{c}93 \pm 15 \\
(\mathrm{NS})\end{array}$ & $\begin{array}{c}57 \pm 8 \\
(\dagger p<0.005)\end{array}$ & $\begin{array}{c}56 \pm 8 \\
(\S p<0.0001)\end{array}$ & $\begin{array}{c}57 \pm 10 \\
(\S p<0.0001)\end{array}$ & $\begin{array}{c}69 \pm 11 \\
(\dagger p<0.01)\end{array}$ \\
\hline $\mathrm{CO}$ & $2.1 \pm 0.2$ & $\begin{array}{c}1.9 \pm 0.4 \\
(\mathrm{NS})\end{array}$ & $\begin{array}{l}1.9 \pm 0.2 \\
(\mathrm{NS})\end{array}$ & $\begin{array}{c}2.0 \pm 0.2 \\
(\mathrm{NS})\end{array}$ & $\begin{array}{c}2.8 \pm 0.4 \\
(\dagger p<0.006)\end{array}$ & $\begin{array}{c}3.0 \pm 0.4 \\
(\S p<0.0002)\end{array}$ & $\begin{array}{c}3.2 \pm 0.5 \\
(\S p<0.0002)\end{array}$ & $\begin{array}{c}3.1 \pm 0.8 \\
(\dagger p<0.001)\end{array}$ \\
\hline $\mathrm{HR}$ & $126 \pm 18$ & $\begin{array}{c}115 \pm 19 \\
(\mathrm{NS})\end{array}$ & $\begin{array}{c}113 \pm 14 \\
(\mathrm{NS})\end{array}$ & $\begin{array}{c}149 \pm 19 \\
(\mathrm{NS})\end{array}$ & $\begin{array}{c}151 \pm 16 \\
(\dagger p<0.005)\end{array}$ & $\begin{array}{c}155 \pm 19 \\
(\S p<0.005)\end{array}$ & $\begin{array}{c}160 \pm 30 \\
(\S p<0.005)\end{array}$ & $\begin{array}{c}165 \pm 32 \\
(\dagger p<0.005)\end{array}$ \\
\hline
\end{tabular}

MPAP, MAP in mm Hg. PVR, SVR in dyne $\mathrm{s} \mathrm{cm}^{-5}$. CO in L $\mathrm{min}^{-1}$. HR in beats $\mathrm{min}^{-1}$. NO in ppm. Dip $100=$ dipyridamole $100 \mu \mathrm{g} / \mathrm{kg} / \mathrm{min}$. Stop Dip $100=$ Dip $100+$ NO discontinued for 20 min.

* U-46619 vs baseline. † Dip 100 or NO vs U-46619. § Dip $100+$ NO vs NO alone (equal concentrations). $n=12$.

dose of NO and limit potential toxicity related to NO inhalation $(20,21)$. Although the experimental PDE 5 inhibitor zaprinast (generic name) is slightly more potent than dipyridamole (4) and has already been used to enhance the effects of inhaled NO $(22,23)$, we preferred to study dipyridamole because it is an approved, inexpensive drug that has been clinically available for more than $30 \mathrm{y}$. If dipyridamole potentiates the effects of inhaled NO without compromising the systemic circulation, it can be useful in the setting of PHT in neonates and infants after surgery for congenital heart disease.

Our study shows that low-dose i.v. dipyridamole $(10 \mu \mathrm{g} / \mathrm{kg} /$ min) is not a selective pulmonary vasodilator, but reduces MPAP and PVR, with a significant reduction in SVR but a clinically acceptable decrease in MAP (Table 1). Whereas inhaled NO (protocol 1) significantly vasodilates pulmonary blood vessels (MPAP $-29 \%$, PVR $-43 \%, 20 \mathrm{ppm}$ NO),

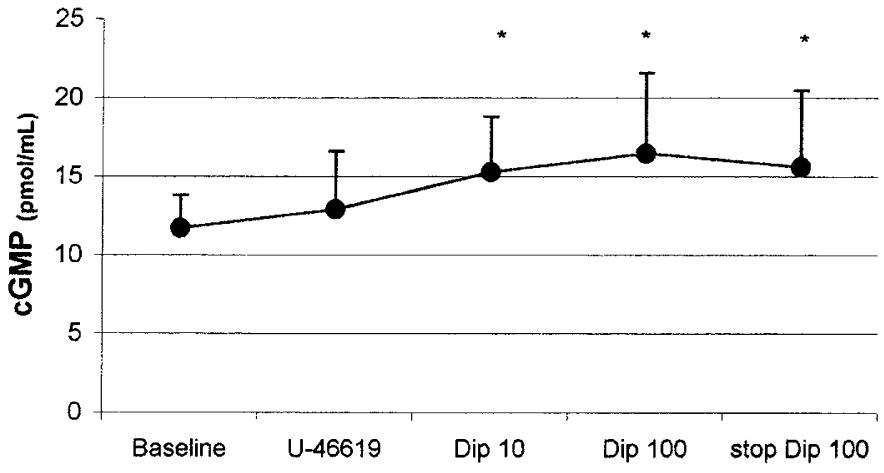

Figure 4. Plasma cGMP levels $(n=8)$ increased significantly with infusion of Dip 10 and Dip 100, and remained elevated 20 min after discontinuation of both NO and Dip 100 (= stop Dip 10). Data are mean \pm SD. ${ }^{*} p<0.05 v s$ baseline. 
dipyridamole in combination with inhaled NO (protocol 2A) further decreases PVR $(-29 \%$, for $20 \mathrm{ppm} \mathrm{NO})$, without significant effect on MPAP $(-6 \%)$ (Table 1). Whether this reflects enhanced pulmonary vasodilation or is merely the result of general vasodilation by dipyridamole is difficult to assess from our data. Although dipyridamole itself increases $\mathrm{CO}$, most probably as a result of systemic vasodilation, the addition of inhaled NO to i.v. dipyridamole further increases $\mathrm{CO}$, with a small decrease in MPAP and an unchanged MAP, suggesting true additional pulmonary vasodilation (Table 1). This increase in $\mathrm{CO}$ can probably be attributed to a decrease in right ventricular afterload with maintained coronary perfusion, resulting in improved right ventricular function.

Although in the present study $100 \mu \mathrm{g} / \mathrm{kg} / \mathrm{min}$ dipyridamole (protocol 2B) decreased MPAP and reduced PVR more than any concentration of NO studied (Table 2), this dose is unacceptable in clinical practice because of the systemic hypotension it induces. Additionally, the combination of decreased coronary perfusion pressures and increased heart rate can be deleterious for right and left ventricular function as well as myocardial oxygen balance. Despite a possible residual effect of the low-dose dipyridamole, the abrupt decrease in MPAP, MAP, PVR, and SVR on initiation of $100 \mu \mathrm{g} / \mathrm{kg} / \mathrm{min}$ i.v. suggests this high dose to be responsible for the potentially dangerous effects on systemic hemodynamics.

Interestingly, low-dose dipyridamole combined with 2.5 ppm NO reduces PVR more than 20 ppm NO alone, with a clinically acceptable decrease in MAP (Table 1). In clinical practice, this might allow the use of much lower doses of inhaled $\mathrm{NO}$, thereby reducing the potential toxicity related to NO inhalation, such as methemoglobinemia (24), oxidation of $\mathrm{NO}$ to $\mathrm{NO}_{2}(25)$, and $\mathrm{NO}_{2}$-related bronchospasm in humans (20). Furthermore, very little is known about the oxidant stress from the production of peroxynitrite (21) in patients with lung inflammation and in immature babies likely to have decreased antioxidant defenses (10). Although the toxicity issue of $\mathrm{NO}$ inhalation is not yet resolved, in the absence of in vivo studies addressing safe duration and dosage of NO inhalation, the combination of dipyridamole with low inhaled NO concentrations can be considered to reduce potential $\mathrm{NO}$ and $\mathrm{NO}_{2}-$ related toxicity.

Our results are similar to those obtained by Ziegler et al. (26) in pediatric patients with severe PHT. The authors report a decrease in PVR and SVR with dipyridamole alone, and a further reduction by $20 \%$ in PVR in half of the patients when NO and dipyridamole are combined. In contrast to these and our data, Fullerton et al. (27) report i.v. dipyridamole in combination with inhaled NO to cause selective pulmonary vasodilation in patients immediately after mitral or aortic valve surgery. The authors also reported an increase in $\mathrm{CO}(+50 \%)$ similar to what we have found when dipyridamole and $\mathrm{NO}$ are combined. The longstanding left atrial and pulmonary venous hypertension and the relatively low dose of dipyridamole administered in their study may account for the selective nature of the pulmonary vasodilation.

Rebound PHT on withdrawal of inhaled NO after congenital heart surgery $(12,28,29)$ and in severe respiratory failure $(13)$ has been described previously. The dangers of rebound PHT are not only related to an abundant increase in pulmonary artery pressure, jeopardizing right ventricular function, but also to a sudden "rebound" decrease in arterial oxygen saturation (13). Because there is evidence that NO itself inhibits NO synthase activity in various tissues via a feedback mechanism (30), a possible explanation for the phenomenon of rebound PHT is inhibition of endogenous NO production in the pulmonary vascular endothelium during NO inhalation, combined with a reduced NO production after sudden withdrawal of inhaled NO (31). When endogenous pulmonary NO production cannot be restored instantly after discontinuation of NO inhalation, we speculate that drugs that prolong the half-life of NO's second messenger, cGMP, may be useful to prevent rebound PHT.

Although there is increasing evidence that dipyridamole augments the effects of inhaled $\mathrm{NO}(22,27,32)$ and may be useful in patients who cannot be weaned easily from $\mathrm{NO}$ inhalation (33), there is only one report that addresses the potential of dipyridamole to attenuate rebound PHT after withdrawal of inhaled NO (29). The obvious hypothesis for this phenomenon is that dipyridamole reduces the breakdown of increased cGMP levels resulting from NO inhalation in pulmonary vascular smooth muscle cells. Although increased plasma cGMP levels during zaprinast infusion and cGMP release from the lungs during combined treatment with i.v. zaprinast and inhaled NO have been described (23), to the best of our knowledge the present study is the first to address the role of increased cGMP levels during dipyridamole infusion in the setting of rebound PHT. Our data show that i.v. dipyridamole increases plasma cGMP concentrations. The long halflife of i.v. dipyridamole (between 12 and 15 h) (34) may well explain why, even $20 \mathrm{~min}$ after both dipyridamole and $\mathrm{NO}$ were discontinued, cGMP levels were significantly elevated (Fig. 4) and pulmonary artery pressures were similar to those during dipyridamole infusion (Table 2). We hypothesize that the increased plasma cGMP levels measured in our study reflect, to some extent, intrapulmonary vascular smooth muscle cGMP concentrations and, therefore, may protect against rebound PHT after sudden withdrawal of inhaled NO. Although slowly weaning the NO is usually sufficient to avoid rebound PHT in most instances, this technique may be cumbersome and low-dose dipyridamole may be a valuable alternative when weaning from $\mathrm{NO}$ is difficult.

\section{Study Limitations}

The increased plasma cGMP levels in our study cannot solely be attributed to the release of cGMP from pulmonary blood vessels, but other tissues such as systemic blood vessels may be involved. Another putative mechanism of vasodilation by dipyridamole includes inhibition of adenosine re-uptake (35). However, the evidence that pulmonary vasodilation by dipyridamole is not altered by adenosine receptor blockers such as theophylline but is exerted through an effect on cGMP metabolism $(15,32)$, and the fact that i.v. dipyridamole can prevent rebound PHT, suggest that cGMP concentrations in pulmonary vascular smooth muscle cells are increased by dipyridamole. 
From our results, it is difficult to conclude whether dipyridamole induces true pulmonary vasodilation. Although it decreases MPAP, the reduction in PVR is mainly the result of an increase in $\mathrm{CO}$ and may indicate recruitment of pulmonary arterioles. However, the setting of a decrease in pulmonary artery pressure in combination with an important increase in pulmonary blood flow suggests at least a component of direct pulmonary vasodilation. Comparison of these data with those obtained with an inotropic agent, the use of lower doses of dipyridamole, or a more selective PDE 5 inhibitor like sildenafil (36), with probably less effect on the systemic circulation, might resolve this problem. Furthermore, our study design cannot elucidate whether the increase in $\mathrm{CO}$ with dipyridamole should be attributed solely to a reduction in right and left ventricular afterload, or also results from a direct inotropic and chronotropic effect on the myocardium. The fact that the increase in heart rate occurs mainly during the NO withdrawal period (both with and without dipyridamole) further complicates interpretation of these data.

\section{CONCLUSION}

Intravenous dipyridamole enhances the effects of inhaled NO on PHT. It allows lower doses of inhaled NO to be used in this setting, and may thus reduce potential toxicity related to NO inhalation. The combination of both drugs, when properly titrated, may result in adequate reductions of pulmonary artery pressure and right ventricular afterload with clinically acceptable effects on systemic hemodynamics. In clinical practice, i.v. dipyridamole is a promising drug in the setting of neonatal and pediatric cardiac surgery to prevent rebound PHT on withdrawal of inhaled NO, and may be useful in patients who cannot be weaned easily from NO inhalation.

\section{REFERENCES}

1. Furchgott RF, Zawadski JV 1980 The obligatory role of endothelial cells in the relaxation of arterial smooth muscle by acetylcholine. Nature 288:373-376

2. Moncada S, Higgs EA, Hodson HF, Knowles RG, Lopez-Jaramillo P, McCall T, Palmer RMJ, Radomski MW, Rees DD, Schultz R 1991 The L-arginine:nitric oxide pathway. J Cardiovasc Pharmacol 17(suppl 3):1-9

3. Arnold WP, Mittal CK, Katsuki S, Murad F 1977 Nitric oxide activates guanylate cyclase and increases guanosine 3' 5' -cyclic monophosphate levels in various tissue preparations. Proc Natl Acad Sci U S A 74:3203-3207

4. Thomas MK, Sharron HF, Corbin JD 1990 Characterization of a purified bovine lung cGMP-binding cGMP phosphodiesterase. J Biol Chem 265:14964-14970

5. Pepke-Zaba J, Higenbottam TW, Dinh-Xuan AT, Stone D, Wallwork J 1991 Inhaled nitric oxide as a cause of selective pulmonary vasodilatation in pulmonary hypertension. Lancet 338:1173-1174

6. Frostell C, Fratacci MD, Wain JC, Jones R, Zapol WM 1991 Inhaled nitric oxide. A selective pulmonary vasodilator reversing hypoxic pulmonary vasoconstriction. Circulation 83:2038-2047

7. Rossaint R, Falke KJ, Lopez F, Slama K, Pison U, Zapol WM 1993 Inhaled nitric oxide for the adult respiratory distress syndrome. N Engl J Med 328:399-405

8. Kinsella JP, Neish SR, Ivy DD, Shaffer E, Abman SH 1993 Clinical responses to prolonged treatment of persistent pulmonary hypertension of the newborn with low doses of inhaled nitric oxide. J Pediatr 123:103-108
9. Wessel DL, Adatia I, Giglia TM, Thompson JE, Kulik TJ 1993 Use of inhaled nitric oxide and acetylcholine in the evaluation of pulmonary hypertension and endothelial function after cardiopulmonary bypass. Circulation 88:2128-2138

10. Roberts JD, Lang P, Bigatello LM, Vlahakes GJ, Zapol WM 1993 Inhaled nitric oxide in congenital heart disease. Circulation 87:447-453

11. 1988 NIOSH recommendations for occupational safety and health standards 1988 . MMWR Morb Mortal Wkly Rep 37(suppl 7):1-29

12. Atz AM, Adatia I, Wessel DL 1996 Rebound pulmonary hypertension after inhalation of nitric oxide. Ann Thorac Surg 62:1759-1764

13. Lavoie A, Hall JB, Olson DM, Wylam ME 1996 Life-threatening effects of discontinuing inhaled nitric oxide in severe respiratory failure. Am J Respir Crit Care Med 153:1985-1987

14. Braner DAV, Fineman JR, Chang R, Soifer SJ 1993 M\&B 22948, a cGMP phosphodiesterase inhibitor, is a pulmonary vasodilator in lambs. Am J Physiol 264:H252$\mathrm{H} 258$

15. Ziegler JW, Ivy DD, Fox JJ, Kinsella JP, Clarke WR, Abman SH 1995 Dipyridamole, a cGMP phosphodiesterase inhibitor, causes pulmonary vasodilation in the ovine fetus. Am J Physiol 269:H473-H479

16. Cohen AH, Hanson K, Morris K, Fouty B, Mc Murty IF, Clarke W, Rodman DM 1996 Inhibition of cyclic 3' - 5' - guanosine monophosphate-specific phosphodiesterase selectively vasodilates the pulmonary circulation in chronically hypoxic rats. J Clin Invest 97:172-179

17. Stamler JS, Loh E, Roddy MA, Currie KE, Creager MA 1994 Nitric oxide regulates basal systemic and pulmonary vascular resistance in healthy humans. Circulation 89:2035-2040

18. Celermajer DS, Dollery C, Burch M, Deanfield JE 1994 Role of endothelium in the maintenance of low pulmonary vascular tone in normal children. Circulation 89:2041-2044

19. Giaid A, Saleh D 1995 Reduced expression of endothelial nitric oxide synthase in the lungs of patients with pulmonary hypertension. N Engl J Med 333:214-221

20. Bauer MA, Utell MJ, Morrow PE, Speers DM, Gibb FR 1986 Inhalation of 0.30 ppm nitrogen dioxide potentiates exercise-induced bronchospasm in asthmatics. Am Rev Respir Dis 134:1203-1208

21. Beckmann JS, Beckmann TW, Chen J, Marshall PA, Freeman BA 1990 Apparent hydroxyl radical production by peroxynitrite: implications for endothelial injury from nitric oxide and superoxide. Proc Natl Acad Sci U S A 87:1620-1624

22. Thusu KG, Morin FC, Russell JA, Steinhorn RH 1995 The cGMP phosphodiesterase inhibitor zaprinast enhances the effect of nitric oxide. Am J Respir Crit Care Med 152:1605-1610

23. Ichinose F, Adrie C, Hurford WE, Zapol WM 1995 Prolonged pulmonary vasodilator action of inhaled nitric oxide by zaprinast in awake lambs. J Appl Physiol 78:12881295

24. Wessel DL, Adatia I, Thompson JE, Hickey PR 1994 Delivery and monitoring of inhaled nitric oxide in patients with pulmonary hypertension. Crit Care Med 22:930938

25. Foubert L, Fleming B, Latimer RD, Jonas M, Oduro A, Borland C, Higenbottam TW 1992 Safety guidelines for use of nitric oxide. Lancet 339:1615-1616

26. Ziegler JW, Ivy DD, Wiggins JW, Kinsella JP, Clarke WR, Abman SH 1998 Effects of dipyridamole and inhaled nitric oxide in pediatric patients with pulmonary hypertension. Am J Respir Crit Care Med 158:1388-1395

27. Fullerton DA, Jaggers J, Piedalue F, Grover FL, McIntyre RC 1997 Effective control of refractory pulmonary hypertension after cardiac operations. J Thorac Cardiovasc Surg 113:363-370

28. Miller OI, Tang SF, Keech A, Celermajer DS 1995 Rebound pulmonary hypertension on withdrawal from inhaled nitric oxide. Lancet 346:51-52

29. Ivy DD, Kinsella JP, Ziegler JW, Abman SH 1998 Dipyridamole attenuates rebound pulmonary hypertension after inhaled nitric oxide withdrawal in postoperative congenital heart disease. J Thorac Cardiovasc Surg 115:875-882

30. Buga GM, Giscavage JM, Rogers NE, Ignarro LJ 1993 Negative feedback regulation of endothelial cell function by nitric oxide. Circ Res 73:808-812

31. Oka M, Ohnishi M, Takahashi H, Soma S, Hasunuma K, Sato K, Kira S 1996 Altered vasoreactivity in lungs isolated from rats exposed to nitric oxide gas. Am J Physiol 271:L419-L424

32. Ziegler JW, Ivy DD, Fox JJ, Kinsella JP, Clarke WR, Abman SH 1998 Dipyridamole potentiates pulmonary vasodilation induced by acetylcholine and nitric oxide in the ovine fetus. Am J Respir Crit Care Med 157:1104-1110

33. Al-Alaiyan S, Al-Omran A, Dyer D 1996 The use of phosphodiesterase inhibitor (dipyridamole) to wean from inhaled nitric oxide. Intensive Care Med 22:1093-1095

34. Mosby's Complete Drug Reference 1997, 7th Ed. Mosby-Year Book, St. Louis, p II-207

35. Collis MG, Palmer DB, Saville VL 1985 Comparison of the potency of 8-phenyltheophylline as an antagonist at $\mathrm{A}_{1}$ and $\mathrm{A}_{2}$ adenosine receptors in atria and aorta from the guinea pig. J Pharm Pharmacol 37:278-280

36. Atz AM, Wessel DL 1999 Sildenafil ameliorates effects of inhaled nitric oxide withdrawal. Anesthesiology 91:307-310 